\title{
Encapsulation of Noble Metal Nanoparticles through Seeded Emulsion Polymerization as Highly Stable Plasmonic Systems
}

Leonardo Scarabelli ${ }^{1,2, \dagger, *}$, Marius Schumacher ${ }^{3, \dagger}$, Dorleta Jimenez de Aberasturi ${ }^{1}$, Jan-Philip Merkl $^{3}$, Malou Henriksen-Lacey ${ }^{1}$, Thais Milagres de Oliveira ${ }^{4}$, Marcus Janschel ${ }^{3}$, Christian Schmidtke $^{3}$, Sara Bals ${ }^{4}$, Horst Weller ${ }^{3 *}$, and Luis M. Liz-Marzán ${ }^{1,5 *}$

${ }^{1}$ CIC biomaGUNE and CIBER-BBN, Paseo de Miramón 182, 20014 Donostia-San Sebastián, Spain

${ }^{2}$ Department of Chemistry \& Biochemistry, University of California Los Angeles, Los Angeles, California 90095 USA

${ }^{3}$ Institute of Physical Chemistry, University of Hamburg, 20146 Hamburg, Germany

${ }^{4}$ Electron Microscopy for Materials Science (EMAT), University of Antwerp, Groenenborgerlaan 171, 2020 Antwerp, Belgium

${ }^{5}$ Ikerbasque, Basque Foundation for Science, 48013 Bilbao, Spain

$\dagger$ These authors contributed equally

*Corresponding authors: 1scarabelli@ucla.edu (LS); weller@chemie.uni-hamburg.de (HW); llizmarzan@cicbiomagune.es (LMLM)

\begin{abstract}
The implementation of plasmonic nanoparticles in vivo remains hindered by important limitations such as biocompatibility, solubility in biological fluids, and physiological stability. We present herein a general and versatile protocol, based on seeded emulsion polymerization, for the controlled encapsulation of gold and silver nanoparticles. Our procedure enables the encapsulation of single nanoparticles as well as nanoparticle clusters inside a protecting polymer shell. Specifically, we demonstrate the efficient coating of nanoparticles of both metals, with final dimensions ranging between 50 and $200 \mathrm{~nm}$, i.e. sizes of interest for bio-applications. Such hybrid nanocomposites display extraordinary stability in high ionic strength and oxidizing environments, along with high cellular uptake, and low cytotoxicity. Overall, the prepared nanostructures are promising candidates for plasmonic applications under biologically relevant conditions.
\end{abstract}




\section{Introduction}

The unique interaction of metal nanoparticles with light opens up unexplored avenues for the development of alternative approaches in bioimaging and diagnostics. ${ }^{[1-4]}$ In fact, nanomedicine represents one of the most promising research areas for application of plasmonic nanoparticles, ${ }^{[5,6]}$ related to drug-delivery, ${ }^{[7]}$ photothermal therapy, ${ }^{[8]}$ antibacterial surfaces, ${ }^{[9,10]}$ theranostics, ${ }^{[11,12]}$ and biosensing. ${ }^{[13,14]}$

Taking full advantage of the plasmon-engineering capabilities offered by state-of-the-art colloidal synthetic methods, ${ }^{[15]}$ both gold and silver nanoparticles have been implemented as bioimaging probes, ${ }^{[3]}$ exploiting different spectroscopies, e.g. surface enhanced Raman scattering (SERS), surface enhanced fluorescence (SEF) and surface enhanced IR absorption (SEIRA) spectroscopy. ${ }^{[16-18]}$ The ability of plasmons to efficiently decay through coupling to phonons can potentially enable the combination of sensing and therapy, using hyperthermia to directly damage target cells, or to trigger the in situ release of a cargo. ${ }^{[11]}$ For example, Topete et al. demonstrated a nanotheranostic platform made of poly(lactic-co-glycolic acid)/doxorubicin-core@Au-branched shell nanostructures, ${ }^{[19]}$ whereas Chen et al. reported a theranostic system obtained by coencapsulation of iron oxide nanoparticles and gold nanorods inside mesoporous silica beads, which displayed multimodal imaging ability, combined with improvements in stroke therapy. ${ }^{[20]}$ More recently, Kolovskaya et al. proposed high anti-cancer activity of aptamer-conjugated, spherical gold nanoparticles in tumor bearing mice upon photothermal treatment. ${ }^{[21]}$ Despite these efforts, several challenges are still to be overcome before nanoplasmonics can be implemented as a tool for in vivo biosensing and bioimaging. The biocompatibility/toxicity of plasmonic nanoparticles has been linked to their size, shape, and surface chemistry, ${ }^{[22-25]}$ and in the case of silver, to their easy oxidation leading to release of $\mathrm{Ag}^{+}$ions. ${ }^{[9,26-30]}$ Moreover, the exposure to complex biological environments has been shown to have drastic effects on the stability and pharmacokinetics of noble metal nanoparticles. ${ }^{[31,32]}$ Phenomena like protein corona formation, ${ }^{[33]}$ shear forces inside the blood stream, changes in $\mathrm{pH}$ or temperature, ${ }^{[26]}$ or immune system activity, ${ }^{[34,35]}$ must be taken into account. As a matter of fact, the design of plasmonic diagnostic and theranostic nanosystems for application under in vivo conditions gets complicated by issues such as oxidation, unwanted ligand exchange, unspecific cellular uptake, and biodegradation. ${ }^{[36]}$ These problems have led to the development of a variety of coating strategies, ${ }^{[37]}$ involving polymers, ${ }^{[38-43]}$ di-block and tri-block copolymers, ${ }^{[44-46]}$ silica-shells, ${ }^{[20,47-49]}$ and lipid or peptide based coatings. ${ }^{[50,51]}$ Some of us have 
recently demonstrated the encapsulation and stabilization of hydrophobic nanoparticles (quantum dots, quantum rods, iron oxide NPs) in aqueous media, using seed emulsion polymerization techniques. ${ }^{[52-56]}$ Remarkably, the polymer shells obtained through this procedure were reported to provide excellent shielding in biological environments. ${ }^{[53,57]} \mathrm{We}$ demonstrate hereby the successful application of a similar process to the generalized encapsulation of plasmonic nanoparticles composed of either gold or silver, with the ability to encapsulate either single or clustered nanoparticles, by simply varying the nanoparticle(ligand)/block copolymer ratio. The possibility of precisely tuning the overall size, from a single nanoparticle up to $200 \mathrm{~nm}$ clusters, is of paramount importance for both in vitro and in vivo applications, as size is an essential parameter regulating nanoparticle cellular uptake. ${ }^{[58,59]}$ Grzelczak et al. have developed a similar polymer encapsulation strategy for gold colloids based on hydrophobic interactions, but skipping the crosslinking step and with limited variation of polymer chain length. ${ }^{[44]}$ Our findings show that the formation of a highly cross-linked polymer shell not only confers to the particles high stability in biological media, but also provides high resistance against extreme oxidizing conditions (e.g. up to $24 \mathrm{~h}$ in $10 \%$ aqua regia solution). The prepared nanostructures were incubated with different cell lines to address their biocompatibility and bio-stability, showing high cell viability ratios for all tested conditions, in combination with high cellular uptake. Electron microscopy/tomography analysis of incubated cells demonstrates the intracellular stability of the nanostructures, with a clearly visible polymer coating, even after uptake inside endosomes. ${ }^{[34,60]}$

The seeded emulsion polymerization methodology proposed here presents two important advantages over previous methods: i) interparticle distances below $3 \mathrm{~nm}$ within the clusters (leading to plasmon coupling and hot spot formation); ii) remarkable resistance towards high-ionic strength environment and extreme oxidizing conditions. Additionally, the proposed multi-step strategy offers wide-ranging opportunities of adaptation to specific targets and applications, ranging from the co-encapsulation of different nanoparticles and molecules, ${ }^{[53]}$ through the chemical modification of the polymeric shell, ${ }^{[57]}$ to the grafting of specific biomolecules to the cluster surface. ${ }^{[52]}$ As such, this work represents a step forward toward the stabilization of plasmonic nanoparticles for in vivo applications, with potential uses as SERS bioimaging tags, photothermal therapy agents, and drug delivery systems. 


\section{Results and Discussion}

The present approach is based on a seeded emulsion polymerization technique developed by Weller and co-workers, ${ }^{[54,61]}$ which involves three separate steps (Scheme 1): (i) ligand exchange reaction with poly(isoprene)-diethylentriamine, PI-DETA; (ii) encapsulation of the hydrophobic nanoparticles in aqueous media, inside a supramolecular system formed upon addition of poly(isoprene)-block-poly(ethylene oxide), PI- $b$-PEO (also named PI- $b$-PEG); and (iii) seeded emulsion polymerization performed in the hydrophobic part of the system, yielding a cross-linked, protective polystyrene shell.

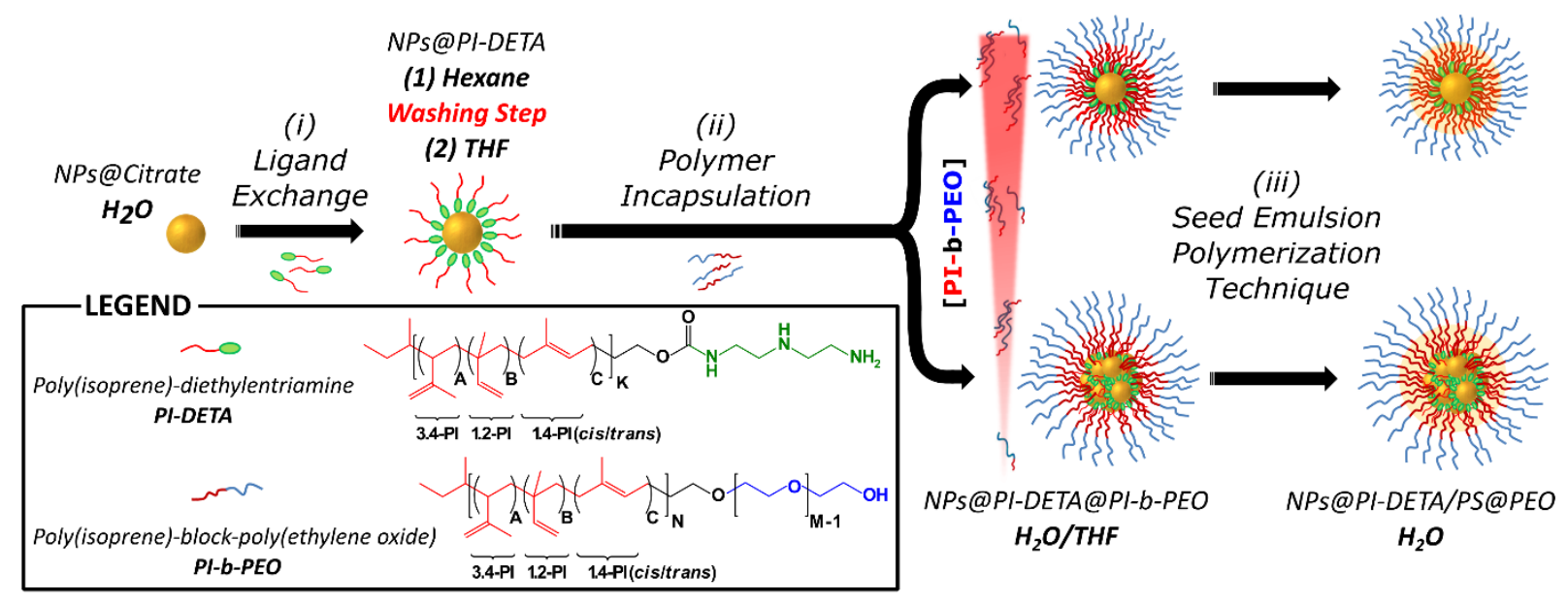

Scheme 1. Schematic representation of the three-step procedure for the encapsulation of hydrophilic nanoparticles using PI-DETA, PI- $b$-PEO di-block copolymer and seeded emulsion polymerization.

Citrate coated gold and silver nanoparticles in aqueous dispersion were selected as model plasmonic nanoparticles. ${ }^{[62,63]}$ Even though both gold and silver spherical nanoparticles can be directly synthesized in organic solvents, demonstration of the encapsulation of initially hydrophilic particles provides more extensive generality to the method, e.g. toward the encapsulation of anisotropic nanoparticles (with plasmon resonances within the biological transparency window: $650-1350 \mathrm{~nm}$ ). Although synthetic routes in organic media are limited for such particles, successful transfer from water and stabilization in non-polar solvents have been reported, and can be adapted to the protocol proposed here. ${ }^{[56,64,65]}$ The ligand exchange reaction (step (i) in Scheme 1) was performed by emulsifying an aqueous suspension of nanoparticles together with a hexane solution of PI-DETA, through vigorous magnetic stirring (Experimental Section). The coloration of the organic phase and simultaneous discoloration of the aqueous phase, along with UV-vis 
investigations, confirm successful ligand exchange and nanoparticle phase transfer (insets in Figure 1C, E). The protocol was optimized by adjusting the number of PI-DETA equivalents to be added to the organic phase (see Supporting Information, Figure S1). We found that a minimum of 3000 PI-DETA molecules per particle are required for the effective phase transfer of $19 \pm 2 \mathrm{~nm}$ gold nanoparticles (Figures S2-S4). This corresponds to approximately 3 ligand molecules per $\mathrm{nm}^{2}$ of gold surface, in line with the values reported in previous studies for similar polymer ligands. ${ }^{[66,67]}$ It is important to note that nanoparticle phase transfer does not work in basic $\mathrm{pH}$, at which amine moieties are deprotonated (Supporting Information, Table T1); this suggests that the charge of the anchoring group is a determining factor, probably related to the ability of the amphiphilic polymer to form micelles in water. ${ }^{[68]}$ Further details on the optimization can be found in the Supporting Information (Figures S1-S4). The protocol was successfully adapted to $42 \pm 9$ $\mathrm{nm}$ silver nanoparticles, using the same PI-DETA surface density as that used for gold nanoparticles (insets in Figure 1D, F). For both metals, UV-Vis extinction spectra before and after ligand exchange show the expected red-shift due to increased refractive index (upon ligand exchange and transfer from water to hexane), with no evidence of aggregation (Figure 1A). Optical data were confirmed by dynamic light scattering (DLS) analysis. For both gold and silver we observed an increase of the hydrodynamic radius by $8 \mathrm{~nm}$ (24 to $32 \mathrm{~nm}$ for gold; 60 to $68 \mathrm{~nm}$ for silver, see grey areas in Figure 1B), which confirms the exchange of citrate by the polymeric ligand PI-DETA (Figure 1B). TEM images confirmed that the average size distribution of the metallic colloids remained unaltered upon ligand exchange $(19 \pm 3 \mathrm{~nm}$ to $19 \pm 2 \mathrm{~nm} ; 42 \pm 9 \mathrm{~nm}$ to $41 \pm 8 \mathrm{~nm}$, for gold and silver respectively, see Figure 1C-F). The presence of the PI-DETA shell cannot be appreciated through electron microscopy, as the molecular weight of the polymer, and consequently the length of the chain, are too low to offer any contrast around metal particles of this size. 

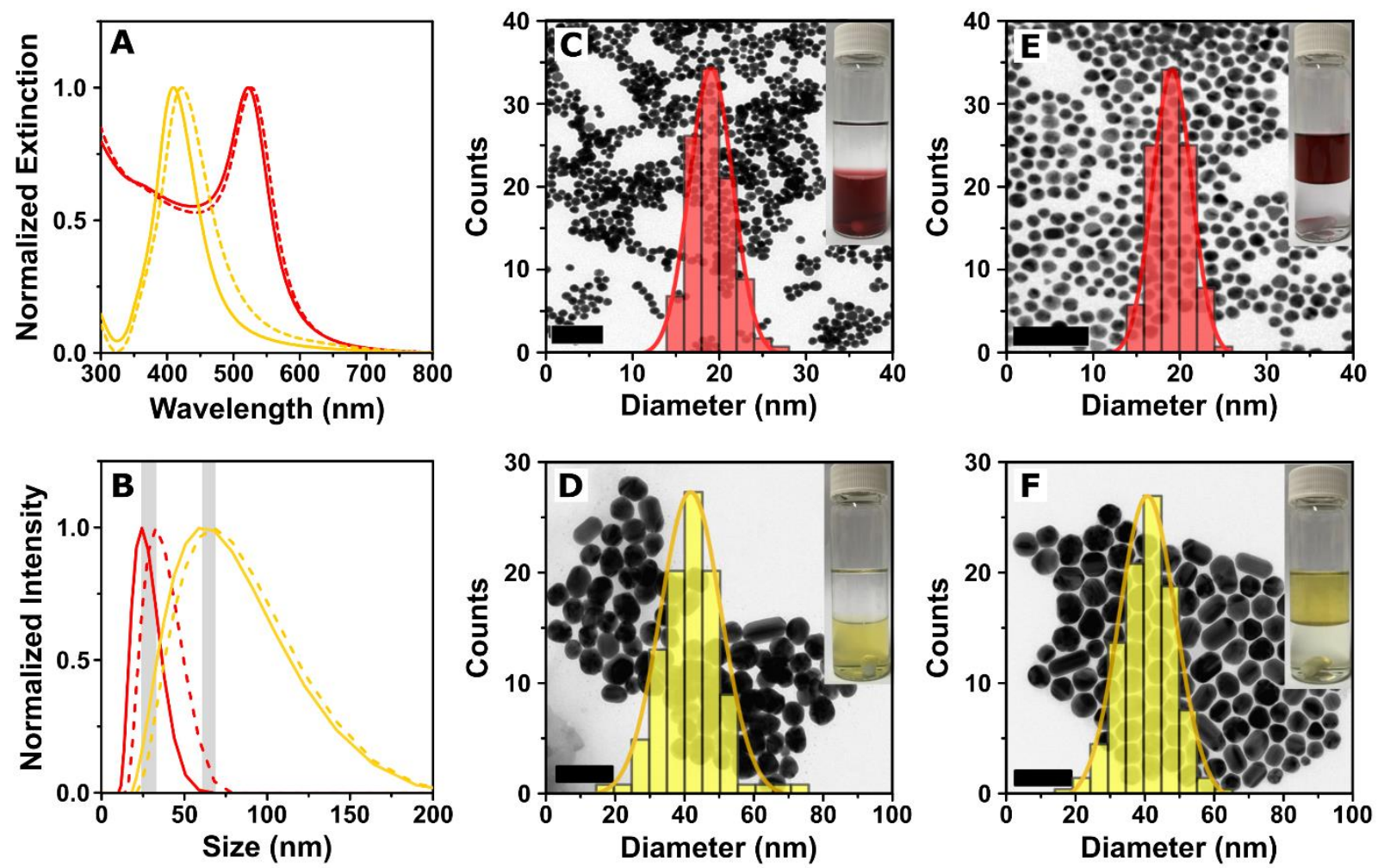

Figure 1. Normalized UV-vis spectra (A), and DLS analysis (B, intensity distribution), of citrate- (solid lines) and PI-DETA- (dotted lines) capped gold (red lines) and silver (yellow lines) nanoparticles. The grey areas in $\mathbf{B}$ highlight the difference in hydrodynamic diameter between citrate-, and PI-DETA-capped colloids. C-F: TEM images and size histograms for gold $(\mathbf{C}, \mathbf{E})$ and silver $(\mathbf{D}, \mathbf{F})$ nanoparticles, before $(\mathbf{C , D})$ and after (E,F) ligand exchange (100 particles were counted in each case). Scale bars: $100 \mathrm{~nm}$. Insets: photographs of the two-phase system used for ligand exchange (hexane over water).

The hydrophobic colloids obtained upon ligand exchange with PI-DETA can be dried and readily redispersed in THF, showing high stability over long periods of at least 6 months (Figure S5). PIDETA coated nanoparticles were subsequently transferred back into water, using an amphiphilic PI- $b$-PEO di-block-copolymer: hydrophobic interactions between poly(isoprene) chains on the particles and in the copolymer, trigger the formation of a supramolecular micellar system (step (ii) in Scheme 1). This procedure can be applied, not only to the encapsulation of single nanoparticles but also to clusters of different sizes by simply changing the molar ratio between NPs@PI-DETA and PI- $b$-PEO. ${ }^{[56,69]}$ The mixture of both components is readily achieved using a microfluidic system with suitable mixing chambers (see Experimental Section and Figure S6 for details), which provide an excellent control over the shear forces generated during mixing. ${ }^{[69,70]}$ This setup 
prevents high concentration gradients, thereby enabling improved reproducibility in the formation of nanoparticle micelles, as compared to that obtained by manual operation. After encapsulating the particles and dispersing them in water, the final step (iii in Scheme 1) comprises an in situ radical polymerization reaction (see Experimental Section for detailed procedure). Briefly, THF is separated from the nanoparticle aqueous suspension by evaporation at $60{ }^{\circ} \mathrm{C}$ for $15 \mathrm{~min}$, and any remaining residues were removed under vacuum. Styrene and divinylbenzene were then immediately added to the mixture under vigorous stirring, followed by a water-soluble radical initiator to trigger the formation of a polystyrene shell within the hydrophobic part of the system, surrounding the plasmonic core. The obtained samples were then purified by simple centrifugation to remove any unreacted reagents and empty supramolecular micelles. By varying the PI- $b$ PEO:PI-DETA molar ratio, both gold or silver nanoparticle clusters could be obtained (Figures 2 and S7). We expected that the addition of a lower amount of PI- $b$-PEO would lead to the formation of bigger clusters, and therefore to an increase in the hydrodynamic radius (Figure $2 \mathbf{C}, \mathbf{D}$ ). Cluster formation should also induce plasmon coupling between co-encapsulated nanoparticles, leading to a red-shift of the plasmon band (Figure 2A, B). Optical and structural analysis indeed confirmed the predicted trends for a supraparticle micellar system (Figure 2), and UV-vis, DLS and TEM data are summarized in Table 1 and in Figures S8, S9. A lower energy plasmon mode becomes more relevant as the dimensions of the clusters increase, in agreement with plasmonic coupling inside the polymer shell (Figure 2A). In the case of the larger silver nanoparticles $(\sim 40 \mathrm{~nm})$ the difference is more pronounced and additional modes can be observed for the bigger clusters (Figure 2B). Electron microscopy analysis revealed the presence of a polymer shell around the metallic cores (Figure 2E, F), as well as the increased size and number of nanoparticles per cluster. 

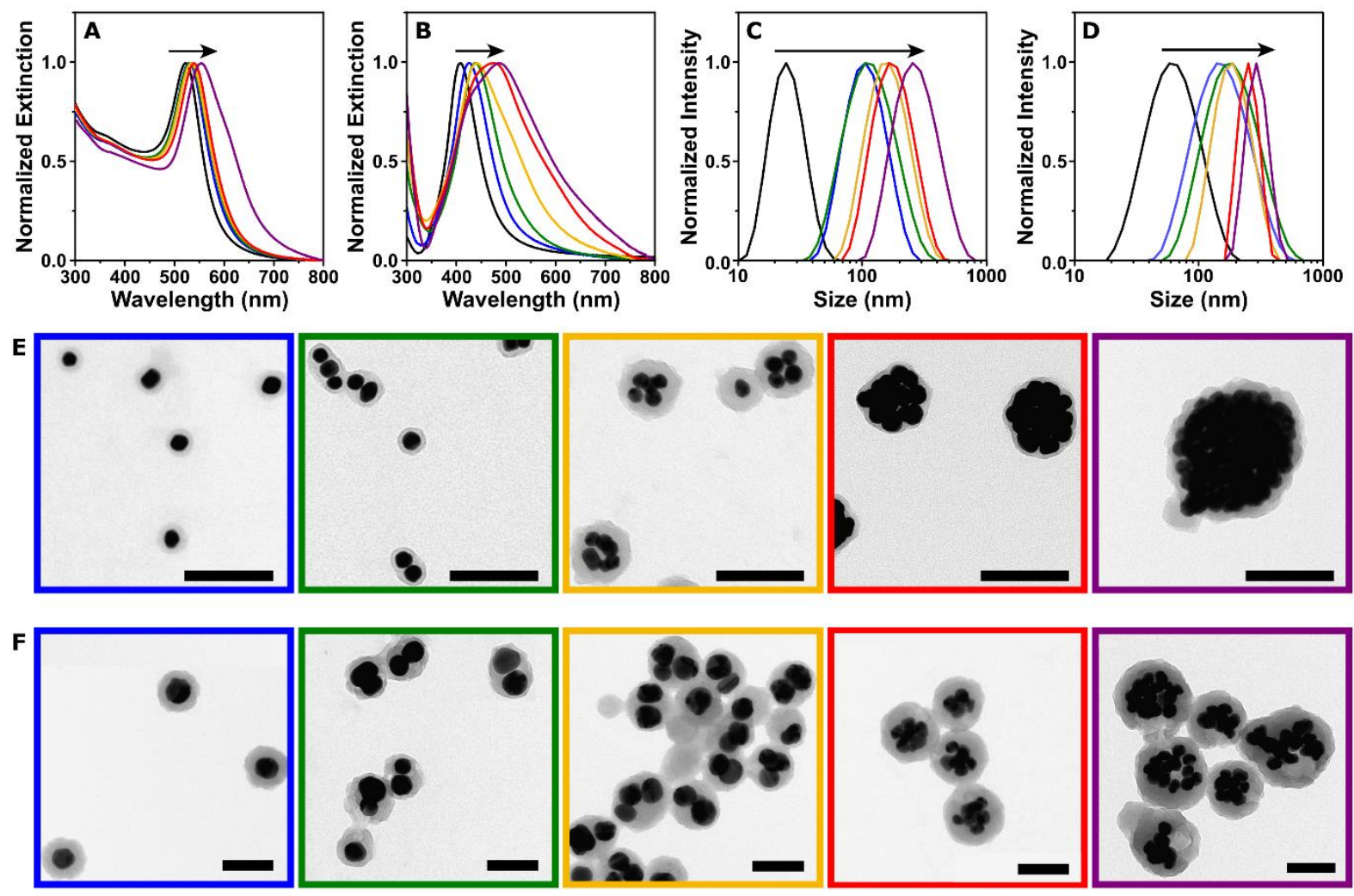

Figure 2. Normalized UV-vis spectra (A, B), and DLS analysis (B, C, intensity distribution), and representative TEM images $(\mathbf{E}, \mathbf{F})$ of single and clustered encapsulated gold $(\mathbf{A}, \mathbf{C}, \mathbf{E})$ and silver $(\mathbf{B}, \mathbf{D}, \mathbf{F})$ nanoparticles, prepared with different molar ratios between PI- $b$-PEO and PI-DETA ligands. Citrate coated nanoparticles (black lines, see TEM in Figure 1); PI- $b$-PEO:PI-DETA ratios: 1:2.5 (blue lines), 1:10 (green lines), 1:20 (yellow lines), 1:30 (red lines), 1:60 (purple lines). The color code is the same for all three analyses. Black arrows underline the red shift of plasmon resonances. Scale bars $=100 \mathrm{~nm}$. Additional low magnification images can be found in the Supporting Information, Figure S7. 


\section{Gold Nanoparticles}

\begin{tabular}{c|ccccc}
\hline PI-b-PEO:PI-DETA & $\mathbf{1 : 2 . 5}$ & $\mathbf{1 : 1 0}$ & $\mathbf{1 : 2 0}$ & $\mathbf{1 : 3 0}$ & $\mathbf{1 : 6 0}$ \\
LSPR $\lambda_{M A X}(\mathrm{~nm})$ & 528 & 531 & 534 & 539 & 552 \\
$D_{H}, D L S(\mathrm{~nm})$ & $112 \pm 45$ & $124 \pm 58$ & $168 \pm 68$ & $186 \pm 73$ & $286 \pm 121$ \\
$D, T E M(\mathrm{~nm})$ & $34 \pm 3$ & $42 \pm 9$ & $70 \pm 10$ & $70 \pm 15$ & $120 \pm 20$ \\
\hline \multicolumn{7}{c}{ Silver Nanoparticles } \\
\hline PI-b-PEO:PI-DETA & $\mathbf{1 : 2 . 5}$ & $\mathbf{1 : 1 0}$ & $\mathbf{1 : 2 0}$ & $\mathbf{1 : 3 0}$ & $\mathbf{1 : 6 0}$ \\
LSPR $\lambda_{M A X}(\mathrm{~nm})$ & 426 & 439 & 441 & 470 & 487 \\
$D_{H}, D L S(\mathrm{~nm})$ & $171 \pm 73$ & $203 \pm 86$ & $198 \pm 42$ & $259 \pm 54$ & $303 \pm 66$ \\
$D, T E M(\mathrm{~nm})$ & $85 \pm 8$ & $88 \pm 8$ & $100 \pm 10$ & $130 \pm 20$ & $170 \pm 40$ \\
\hline
\end{tabular}

Table 1. Optical and structural data from plots presented in Figure 2 for PI- $b$-PEO-encapsulated gold and silver nanoparticles. LSPR maxima were determined by UV-vis spectroscopy. The intensity weighted mean hydrodynamic diameter $D_{H}$ were determined by DLS. Numbers of nanoparticles per micelle were determined by manual counting of 100 clusters from TEM images (see Figures S8, S9).

Conventional TEM measurements correspond to 2D images of 3D objects and therefore, such an analysis can be misleading for complex three-dimensional objects such as those in this study. ${ }^{[71]}$ We therefore used HAADF-STEM and TEM electron tomography to visualize the clusters in three dimensions (Figure 3). The analysis confirmed that nanoparticle clusters feature a quasi-spherical shape (Video 1, Supporting Material). In order to prevent any flattening or other deformations of the polymer shell in contact with the supporting layer during sample preparation, a freeze-drying approach was applied to the TEM grid under cryo conditions, as explained in detail in the Experimental Section. This allowed us to characterize the nanoparticle packing inside the polymer shell. We found an average interparticle distance of $3 \pm 1 \mathrm{~nm}$ (see Experimental Section for details), which is again in agreement with the observed plasmon coupling and suggests the formation of plasmonic hot spots at the gaps between co-encapsulated particles. This represents an important advantage of our seeded emulsion polymerization approach, as compared to another polymeric encapsulation procedures, where plasmon coupling between co-encapsulated particles is limited by longer interparticle distances. ${ }^{[44]}$ Moreover, by varying the length of the PI-DETA ligands used in the initial step, the interparticle distance can be tuned. Such plasmonic hot spots can be exploited for the development of bioimaging SERS-based tags. ${ }^{[72]}$ 

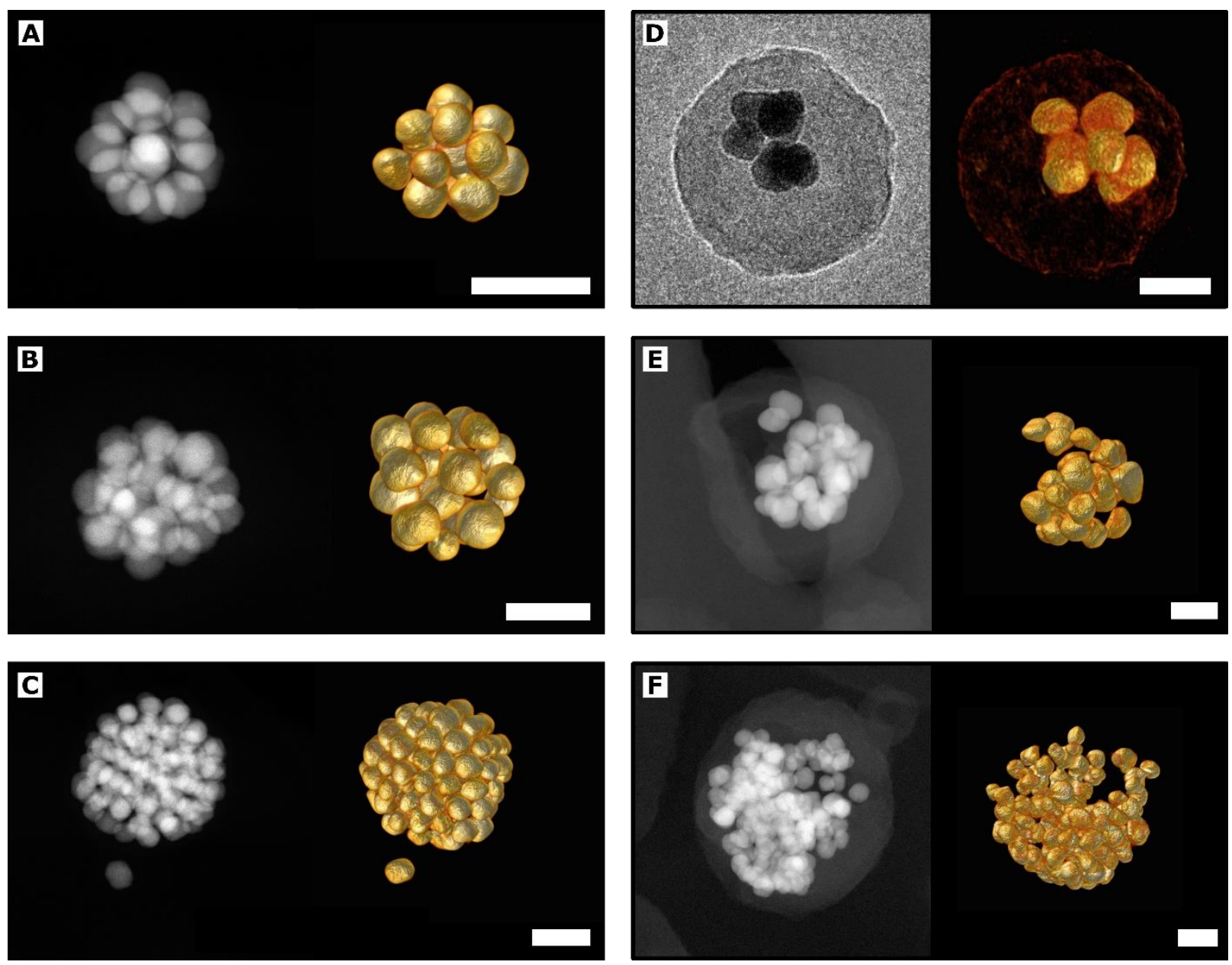

Figure 3. HAADF-STEM images (A-C, E-F left panels), TEM image (D left panel) and electron tomography reconstructions (right panels) of encapsulated clusters made of gold (A-C) and silver (D-F) nanoparticles. Using the $3 \mathrm{D}$ reconstructions it is possible to count the number of particles in each cluster: A: 14 , B: 24, C: 1 | 113, D: 6, E: 31, F: 152 . Scale bars: $50 \mathrm{~nm}$.

The modular character of the encapsulation process enhances its versatility, meaning that it can be adapted to different particle sizes, shapes, and compositions, with tailored interparticle distances, as well as the possibility to encapsulate small molecules and include additional functionalities on the outer surface of the clusters. A potential drawback however, is the limited control over the number of encapsulated NPs and overall cluster size. Standard centrifugation allows eliminating larger aggregates, empty polymer micelles, as well as other organic impurities derived from polymerization (see Experimental Section and Supporting Information). Continuous density gradient centrifugation can be used to further narrow down the size distribution, ${ }^{[69,73]}$ but this technique can only be applied to small volumes (up to $500 \mu \mathrm{L}$ ), and it requires extraction and 
dialysis steps that render the process exceedingly long and cumbersome. Additional details and characterization for this purification procedure are provided in the Supporting Information (Figure S10). We postulate that the formation of a protective polystyrene shell around the metallic core of our plasmonic nanostructures should confer high biocompatibility, protection against oxidizing environments, stability under physiological conditions, and high cellular uptake. We thus investigated the stability of both encapsulated single nanospheres and clusters, made of Au and $\mathrm{Ag}$, before and after seeded emulsion polymerization, under strongly oxidizing conditions. This analysis is of particular relevance in the case of Ag nanoparticles, since the oxidation of metallic silver is considered to be the main reason behind their intrinsic cytotoxicity. ${ }^{[9,27,30]}$ We tested the oxidation of $\mathrm{Au}$ nanostructures by nitric acid $(0.1 \% \mathrm{v} / \mathrm{v})$, aqua regia $(0.1 \% \mathrm{v} / \mathrm{v})$, and potassium cyanide (34 equivalents), whereas silver particles were incubated in solutions of nitric acid $(0.1 \%$ $\mathrm{v} / \mathrm{v})$, aqua regia $(0.1 \% \mathrm{v} / \mathrm{v})$, and hydrogen peroxide $(0.1 \% \mathrm{v} / \mathrm{v})$. Even though nitric acid cannot dissolve metallic gold, the high ionic strength might still induce nanoparticle precipitation, as observed for citrate-capped colloids. Figure 4 summarizes our results, which confirm a remarkably different behavior for encapsulated nanoparticles, as compared to citrate-stabilized colloids. As can be clearly appreciated from UV-vis spectra, all coated samples were stable over 24 hours, whereas citrate-nanoparticle colloids were rapidly oxidized (Figures S11, S12). Encouraged by these results, we also tested stability of nanoparticle clusters under extreme oxidizing conditions, by incubation in a $10 \%$ aqua regia solution. Remarkably, the protective polymer shell was still able to provide stability to the clusters for over $24 \mathrm{~h}$, in contrast to unprotected samples, which were completely oxidized within a few seconds (Figure S13). This high resistance towards chemical oxidation represents another important advantage of our encapsulation strategy, making these hybrid plasmonic nanostructures strong candidates as longlasting tags for in vivo applications. 

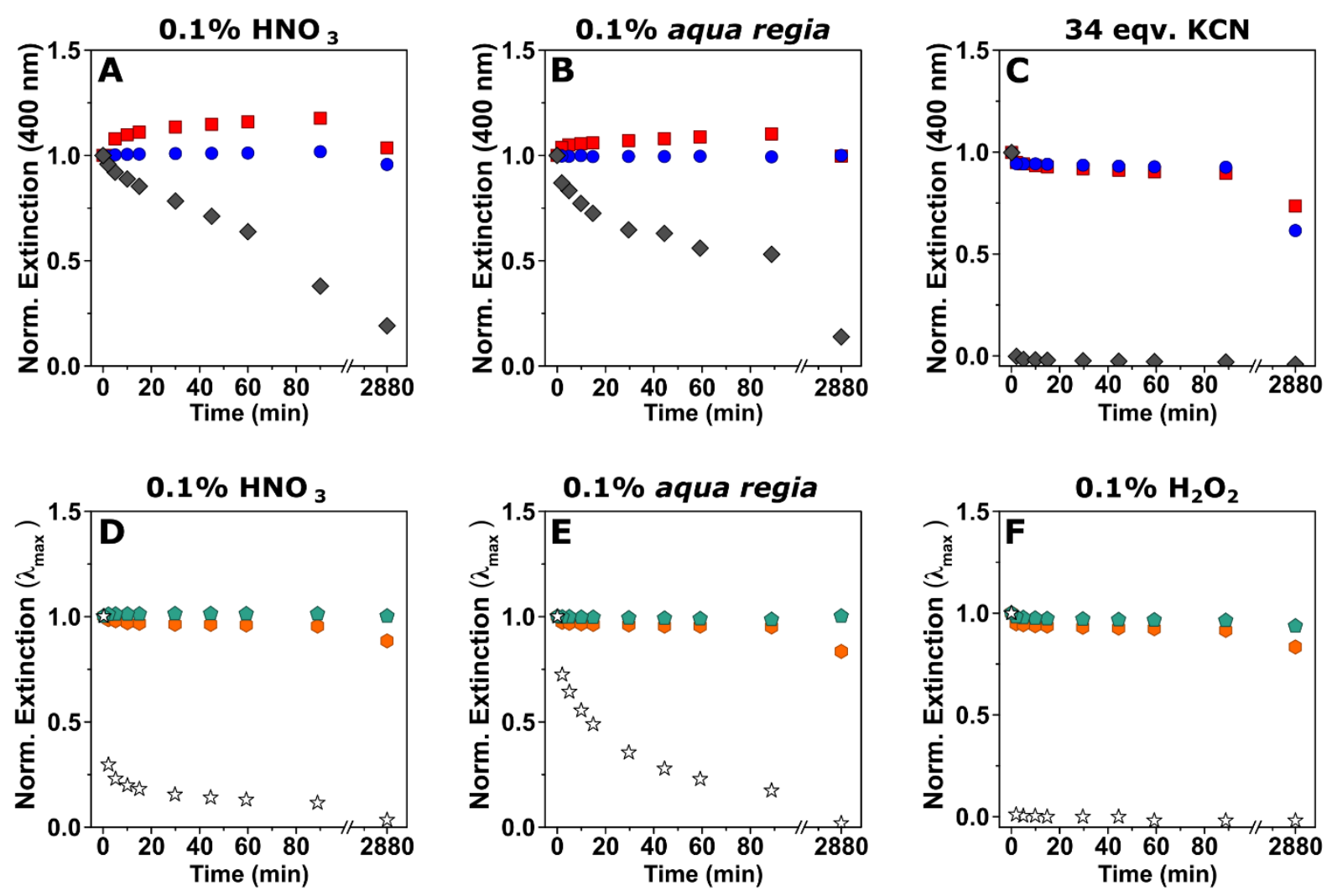

Figure 4. A-C: UV-vis spectroscopy analysis (time traces of the absorbance at $400 \mathrm{~nm}$ ) of the stability of citrate stabilized (grey diamonds), encapsulated single gold nanoparticles (red squares, 1:2.5 PI- $b$ PEO:PI-DETA ratio) and encapsulated gold nanoparticle clusters (blue circles, 1:20 PI- $b$-PEO:PI-DETA ratio), upon incubation with $0.1 \% \mathrm{HNO}_{3}$ (A), $0.1 \%$ aqua regia (B) and $\mathrm{KCN}$ solution (34:1, $\left.\mathrm{n}(\mathrm{KCN}): \mathrm{n}\left(\mathrm{Au}^{0}\right)\right)(\mathbf{C})$. D-F: UV-vis spectroscopy analysis (absorbance at the maximum vs. time ${ }^{[74]}$ ) of the stability of citrate capped (white stars), encapsulated single silver nanoparticles (orange hexagons, 1:2.5 PI- $b$-PEO:PI-DETA ratio) and encapsulated silver nanoparticle clusters (green circles, 1:20 PI- $b$ PEO:PI-DETA ratio) upon incubation with $0.1 \% \mathrm{HNO}_{3}(\mathbf{D}), 0.1 \%$ aqua regia (E) and $0.1 \% \mathrm{H}_{2} \mathrm{O}_{2}(\mathbf{F})$. The corresponding UV-vis spectra are provided in the Supporting Information (Figures S11, S12).

Finally, the in vitro stability and biocompatibility of the synthetized hybrid plasmonic nanostructures were investigated by TEM of fixed and resin embedded mammalian cell samples, as well as by MTT cell viability assays. Three different cell lines were tested: HeLa and A549 as cancerous cell lines, and human dermal fibroblasts (HDF) as healthy primary cells. We observed that exposure of HeLa and A549 cells to concentrations of Au or Ag nanoparticles above $3 \mu \mathrm{M}$ resulted in a decrease of their metabolic activity compared to control cells (Figure 5A, B and Figures S14, S16). Although decreased MTT assay readouts are generally interpreted as a sign of 
reduced cell viability, optical microscopy observations dismissed any nanoparticle-induced cytotoxicity at these concentrations (Figure 5C-F and Figure S15). We thus propose that the high levels of nanoparticle uptake may have an inhibitory effect on the metabolic activity of these highly proliferative cells, as compared to control samples (Figure S15). Indeed, various examples of chemical compounds or nanoparticles causing over/underestimation of cell viability when using the MTT assay can be found in the literature. ${ }^{[75,76]}$ The MTT assay measures the reduction of tetrazolium dye MTT by mitochondrial enzymes, thereby giving information on the cellular metabolic activity, but is not a direct measure of toxicity. ${ }^{[77]}$ Interestingly, MTT results from less metabolically active HDF cells, show levels of cell viability nearly equal to control cells at concentrations up to $30 \mu \mathrm{M}$ for both $\mathrm{Au}$ and $\mathrm{Ag}$, even though the nanoparticle uptake is obviously very high (Figure S16), which further supports our hypothesis.
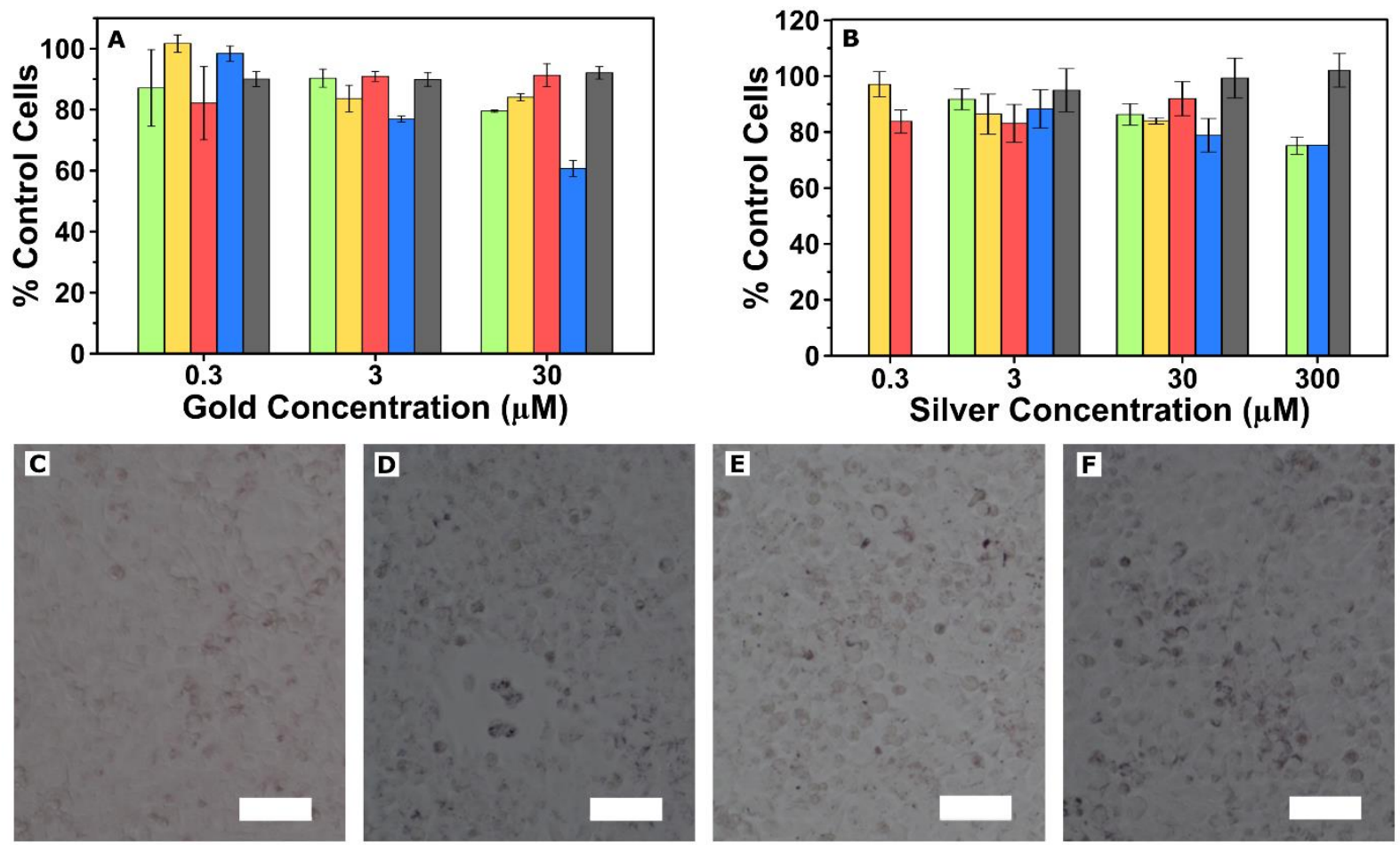

Figure 5. A, B: Metabolic activity of HeLa cells incubated with clusters of different sizes, expressed as $\%$ of control cells, measured with the MTT assay after exposure to different concentrations of Au (A) and $\mathrm{Ag}(\mathbf{B})$ nanoparticles. PI- $b$-PEO:PI-DETA ratios: 1:2.5 (green), 1:10 (yellow), 1:20 (red), 1:30 (blue), citrate colloids (grey). C-F: Light microscopy images of HeLa cells incubated with $30 \mu \mathrm{M}$ encapsulated gold clusters. PI- $b$-PEO:PI-DETA ratio: 1:2.5 (C), 1:10 (D), 1:20 (E), 1:30 (F). Scale bars: $100 \mu \mathrm{m}$. 
We observed that all nanoparticle formulations were endocytosed in high amounts for all three cell lines. In vitro nanoparticle stability was additionally assessed via TEM analysis of HeLa cells exposed to the various gold and silver nanostructure formulations, confirming intracellular stability in all cases (Figure 6 for gold and Figure S17 for silver). Even inside endosomal vesicles where the $\mathrm{pH}$ is commonly more acidic $(\mathrm{pH} \sim 4.5-5.5)$ the polymeric shells around the clusters can be observed with no apparent degradation (Figure 6G-I and Figure S17). The presence of the polymer shell is even more evident when compared to internalized gold and silver nanoparticles that are simply coated with citrate (Figure S18). Moreover, citrate coated silver nanoparticles show clear signs of degradation after internalization (Figure S18). ${ }^{[30,78]}$ 

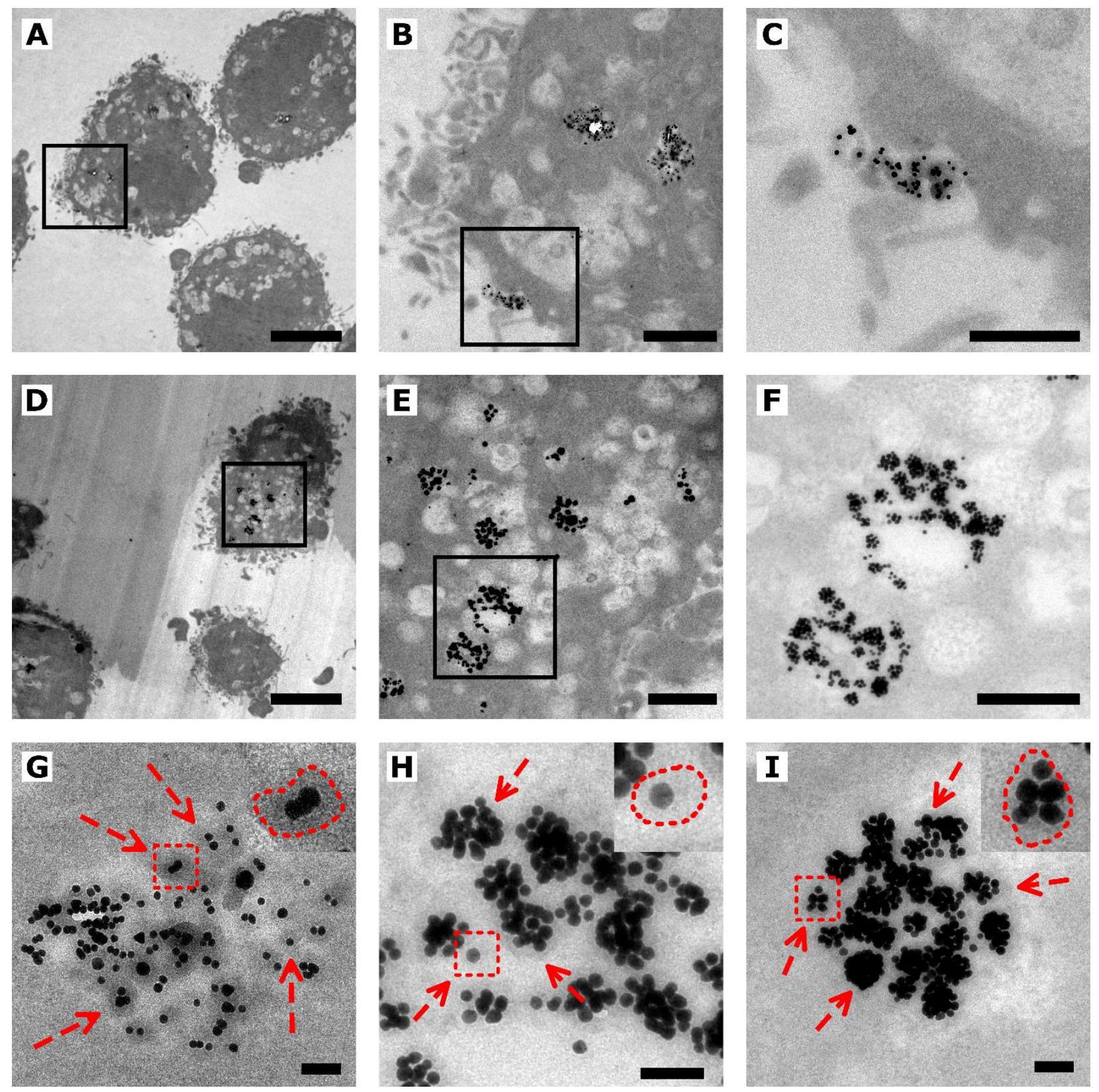

Figure 6. A-F: Representative TEM images at different magnifications showing the cellular uptake by HeLa cells, of gold clusters with PI- $b$-PEO:PI-DETA ratios of 1:10 (A-C), and 1:20 (D-F). G-I: High magnification images of uptaken clusters, where the polymeric shell can be distinguished (red arrows), confirming the stability of clusters after internalization inside endosomal vesicles. Insets: higher magnification images of the dashed red square box areas. The red dashed lines in the insets serve as a guide for the eye, marking the polymeric shells. Scale bars: A, D: $5 \mu \mathrm{m} ; \mathbf{B}, \mathbf{E}: 1 \mu \mathrm{m} ; \mathbf{C}, \mathbf{F}: 500 \mathrm{~nm}$; G-I: $100 \mathrm{~nm}$. 


\section{Conclusions}

A three-step seed emulsion polymerization process was implemented for the encapsulation of plasmonic nanoparticles. This procedure does not impose any limitations on particle size, shape or composition. We focused here on the encapsulation of gold $(19 \pm 2 \mathrm{~nm})$ and silver $(42 \pm 9 \mathrm{~nm})$ nanoparticles. By varying the di-block-copolymer/nanoparticles ratio, the overall size of nanoparticle clusters could be tuned up to $200 \mathrm{~nm}$, by increasing the number of co-encapsulated building blocks. Optical analysis revealed the presence of plasmon coupling between nearby nanoparticles within the clusters, which can potentially be exploited for the enhancement of weak optical signals at hot spots. Most importantly, the polymer shell around the nanoparticles proved to be an effective barrier against both aggregation and oxidation, under high ionic strength and extreme oxidizing conditions, respectively: both gold and silver nanoparticles remained unchanged for over 24 hours, even when immersed in a $10 \%$ aqua regia solution. We demonstrated biocompatibility of encapsulated single particles and clusters, by incubation of $\mathrm{Au}$ and $\mathrm{Ag}$ nanoparticles with three different cell lines, which showed high cell viability despite of very high cellular uptake. Electron microscopy analysis of incubated cells demonstrated the intracellular stability of the nanostructures, with a stable polymer coating, even after uptake into endosomes.

Overall, the proposed strategy represents a significant step forward toward the stabilization of plasmonic nanoparticles for in vivo applications. It is worth noting that the modular nature of our protocol offers the possibility to fine-tune the physicochemical properties of the hybrid systems, which will be the subject of upcoming research, aiming at the development of diagnostic and theranostic nanosystems.

\section{Acknowledgements}

This work was supported by the Spanish MINECO (Grant MAT2017-86659-R), by the German Research Foundation (DFG) via grant LA 2901/1-1 and by the European Research Council 289 (Grant 335078 COLOURATOM to S.B). The authors acknowledge funding from the European Commission Grant (EUSMI 731019 to 292 S.B., L.M.L.-M). L.S. acknowledges funding from the American-Italian Cancer Foundation through a Post-Doctoral Research Fellowship. D.J.d.A. thanks MINECO for a Juan de la Cierva fellowship (IJCI-2015-24264). J.P.M. was financed by 
Verband der Chemischen Industrie e.V. (VCI). We thank Dr. Artur Feld, Dr. Andreas Kornowski and Stefan Werner (Institute of Physical Chemistry, University of Hamburg) for their support.

\section{ASSOCIATED CONTENT}

Supporting Information Available: Additional TEM images, tomographic reconstruction and UV-vis-NIR spectra, analysis of NPs dimensions, discussion on nanoparticle phase transfer, purification by continuous density gradient centrifugation, stability tests, and cellular uptake experiments. This information is available free of charge via the Internet at http://pubs.acs.org/.

\section{EXPERIMENTAL SECTION}

Instrumentration. Ultraviolet-visible (UV-vis) spectroscopy was performed on a Cary 50 (Varian) spectrometer. Dynamic light scattering (DLS) measurements were carried out on a Malvern Zetasizer Nano ZS system with a single angle $173^{\circ}$ backscattering system, using He-Ne laser illumination at $633 \mathrm{~nm}$. Transmission electron microscopy (TEM) images were recorded with a JEOL JEM-1011 microscope (100 keV). High angle annular dark field scanning TEM (HAADFSTEM) and conventional TEM images were acquired using a FEI Tecnai and a FEI Osiris electron microscopes operated at $200 \mathrm{kV}$. The acquisition of electron tomography image series was performed in HAADF-STEM and TEM mode by using a Fischione model 2020 single tilt tomography holder. The series were acquired in the tilt range from $-72^{\circ}$ to $+72^{\circ}$, with tilt increment of $2^{\circ}$. The reconstruction of tilt series was performed using the Astra Toolbox for MATLAB. The visualization of the 3D reconstructions was performed using Amira software.

Freeze-drying procedure. Plunge freezing of the grid was performed with the FEI Vitrobot instrument as follows: the TEM grid is loaded inside the equipment and a drop cast of the solution is deposited on the grid. The excess of liquid is blotted with a filter paper and the grid is immediately immersed in liquid ethane (temperatures $\leq 180{ }^{\circ} \mathrm{C}$ ). The grid was transferred to the Fischione model 2550 cryo-transfer tomography holder in the presence of liquid nitrogen (temperatures $\leq 160{ }^{\circ} \mathrm{C}$ ). Next, heating of the grid is performed inside a vacuum chamber, with pressure below $5 \times 10^{-6}$ mbar and with temperature rate of $+2.6{ }^{\circ} \mathrm{C}$, until room temperature. These 
conditions enabled the phase transition of the vitreous ice layer from solid state to gaseous state without going through liquid state, minimizing the artefacts related with the drying process. ${ }^{[79]}$

Determination of interparticle distance. TEM tomography series were acquired of the cluster prepared after the freeze-drying procedure. In this manner, the delivered dose is smaller when compared with the conventional HAADF-STEM. The definition of interparticle distance corresponds to the distance between the edges of a pair of nanoparticles. This distance was determined through the slices of the three-dimensional reconstruction and the smallest distance here corresponds to the interparticle distance.

Materials. Trisodium citrate (Fluka), ascorbic acid (Sigma Aldrich), hydrogen tetrachloroaurate (Alfa Aesar), silver nitrate (Merck) and 2,2'-azobis[2-(2-imidazolin-2yl)propane]dihydrochloride (VA-044, Wako Chemicals) were used as received from commercial sources. Poly(isoprene)-diethylenetriamine (PI-DETA) and poly(isoprene)-block-poly(ethylene oxide) (PI- $b$-PEO) were provided by CAN GmbH (Center of Applied Nanotechnology, Hamburg, Germany) and prepared via living anionic polymerization according to Pöselt et al. ${ }^{[52]}$ The average molecular weight of PI-DETA $\left(\mathrm{M}_{\mathrm{w}} \sim 1300 \mathrm{~g} \cdot \mathrm{mol}^{-1}\right)$ and PI- $b$-PEO $\left(\mathrm{M}_{\mathrm{w}} \sim 13400 \mathrm{~g} \cdot \mathrm{mol}^{-1}\right.$; $\mathrm{M}_{\mathrm{n}} \sim 12600 \mathrm{~g} \cdot \mathrm{mol}^{-1}$, $\left.65 \mathrm{wt} \% \mathrm{PEO}\right)$ were determined from size-exclusion chromatography analysis. Styrene (analytical grade, Merck) and divinylbenzene (technical grade, 55\% paraisomer), Merck) were purified by distillation. Water was purified using a Purelab Flex 2 system $(18.2 \mathrm{M} \Omega \mathrm{cm})$ and flushed with nitrogen for at least $6 \mathrm{~h}$ before each use. Anhydrous, butylated hydroxytoluene (BHT, $0.025-0.04 \%$ ) stabilized Tetrahydrofuran (THF, VWR Chemicals) was used to prevent peroxide formation and contamination. The other solvents were of analytical grade.

Synthesis of Gold Nanoparticles. A $600 \mathrm{~mL}$ colloid containing 20 nm diameter citrate-stabilized gold nanoparticles was prepared as previously reported. ${ }^{[62]}$ The concentration of colloidal gold was determined from the UV-Vis absorbance at $400 \mathrm{~nm} .{ }^{[80]}$

Synthesis of Silver Nanoparticles. Citrate-stabilized $\sim 40 \mathrm{~nm}$ diameter silver nanoparticles $(250 \mathrm{~mL})$ were synthesized following ref. ${ }^{[81]}$. The concentration of colloidal silver was determined by UV-Vis spectroscopy. ${ }^{[74]}$ 
Ligand Exchange. Nanoparticles were transferred from water into $n$-hexane (VWR Chemicals) upon ligand exchange of citrate by hydrophobic PI-DETA. Then, $12.5 \mathrm{~mL}$ of a citrate-stabilized nanoparticle dispersion was mixed with $7.5 \mathrm{~mL}$ of a PI-DETA $/ n$-hexane solution in a $40 \mathrm{~mL}$ vial. The PI-DETA concentration (c(PI-DETA), Table 2) was adjusted based on the total particle surface area, assuming perfectly spherical objects. Phase transfer was performed by emulsifying the two phases through vigorous magnetic stirring in a closed vial for at least $15 \mathrm{~min}$. Discoloration of the aqueous phase and coloration of the organic phase confirmed ligand exchange and phase transfer (Figure 1). The progress of phase transfer was verified by UV-Vis spectroscopy. On completion, the organic phase was separated by means of a $25 \mathrm{~mL}$ separating funnel. The nanoparticles were stored at $4{ }^{\circ} \mathrm{C}$ in the dark.

Microfluidics Encapsulation. The nanoparticle dispersion in $n$-hexane was centrifuged (9,000 $13,000 \mathrm{~g}, 15 \mathrm{~min}, 10^{\circ} \mathrm{C}$ ). The supernatant was removed, the black precipitate dried thoroughly under nitrogen flow and the nanoparticles resuspended in $1 \mathrm{~mL}$ THF. The suspension was centrifuged again and concentrated to $300 \mu \mathrm{L}$. Subsequently, $500 \mu \mathrm{L}$ THF and a THF/PI- $b$-PEO stock solution (75 $\mu \mathrm{M}, \mathrm{V}(\mathrm{PI}-b$-PEO), Table 2) were added. The PI- $b$-PEO concentration was adjusted based on the molar ratios of PI- $b$-PEO relative to the added amount of the PI-DETA; this ratio will be expressed as PI- $b$-PEO:PI-DETA throughout the manuscript (1:2.5 - 1:60). Nanoparticle encapsulation was realized using a computer-controlled flow system (neMESYS pump from Cetoni, Gera, Germany) equipped with a microfluidic reactor chip consisting of $45 \mu \mathrm{m}$ diameter microfluidic mixing chambers. ${ }^{[82]}$ The THF/nanoparticles@PI-DETA/PI- $b$-PEO solution was mixed with water using the flow system schematized in Figure S6, with a final volume ratio of 1:9. The resulting solution was incubated for $15 \mathrm{~min}$ at room temperature on an orbital shaker at $150 \mathrm{rpm}$.

Seeded Emulsion Polymerization. Emulsion polymerization was carried out under nitrogenatmosphere and all glass devices and stir bars were cleaned with aqua regia and rinsed with DI water before use. The suspension of PI- $b$-PEO encapsulated nanoparticles was diluted with water to $25 \mathrm{~mL}$ in a $50 \mathrm{~mL}$ three-neck round-bottom flask. The solution was then stirred for 15-30 min at $60{ }^{\circ} \mathrm{C}$ to remove the THF. Afterwards, the flask was closed, gently evacuated and again flushed with nitrogen. Subsequently, styrene and divinylbenzene ( $V$ (Styrene) and $V($ DVB), Table 2) were added and incubated for $15 \mathrm{~min}$ in a closed flask under stirring at $60{ }^{\circ} \mathrm{C}$. The amount of monomer 
can be varied depending on the desired shell thickness, if the molar ratio $p$-DVB:Styrene is kept constant at 1:10. To start the polymerization, $100 \mu \mathrm{L}$ of a freshly prepared aqueous solution of the radical initiator 2,2'-Azobis[2-(2-imidazolin-2-yl)propane]dihydrochloride (VA-044, Wako Chemicals, $c$ (VA-044), Table 2) was added. The solution was stirred for $3 \mathrm{~h}$ at $60{ }^{\circ} \mathrm{C}$ in a closed flask. Empty micelles were removed via centrifuging (500 - $3000 \mathrm{~g}, 15 \mathrm{~min}$ ) and discarding the supernatant.

Table 2. Conditions for standard ligand exchange and seeded emulsion polymerization. $c$ (NPs@Citrate) is the concentration of nanoparticles in the initial aqueous colloidal dispersion, $d$ is the average particle diameter (from TEM analysis); PI- $b$-PEO stock solution is $75 \mu \mathrm{M}, V(\mathrm{DVB})$ is based on supplier's indication on para-isomer content.

\begin{tabular}{cccccccc}
\hline & $\begin{array}{c}c \text { (NPs@Citrate }) \\
{[\mathrm{nM}]}\end{array}$ & $\begin{array}{c}d \\
{[\mathrm{~nm}]}\end{array}$ & $\begin{array}{c}c \text { (PI-DETA }) \\
{[\mu \mathrm{M}]}\end{array}$ & $\begin{array}{c}V(\mathrm{PI}-b \text {-PEO }) \\
{[\mu \mathrm{L}]}\end{array}$ & $\begin{array}{c}V \text { (Styrene }) \\
{[\mu \mathrm{L}]}\end{array}$ & $\begin{array}{c}V(\mathrm{DVB}) \\
{[\mu \mathrm{L}]}\end{array}$ & $\begin{array}{c}c(\mathrm{VA}-044) \\
{[\mathrm{mM}]}\end{array}$ \\
\hline Gold & 3.7 & 19.1 & 15.2 & $25-607$ & 6.0 & 1.4 & 60 \\
Silver & 0.2 & 41.7 & 4.1 & $7-166$ & 2.3 & 0.5 & 30 \\
\hline
\end{tabular}

Continuous Density Gradient Centrifugation (CDGC). CDGC was performed according to the protocol of Steinigeweg et al. to obtain well defined cluster sizes. ${ }^{[73]}$ The synthesized colloidal clusters were concentrated to $500 \mu \mathrm{L}$ and stacked on top of the density gradient. The colloids were centrifuged for 60 minutes at $10{ }^{\circ} \mathrm{C}$ and $4300 \mathrm{~g}$ (11180 Swig Out Rotor; Sigma-3-18K). The different fractions were extracted with a horizontal curved hypodermic needle starting from the top, and purified using dialysis (Molecular weight cut-off (MWCO 3.5-5 kD)) for four days, with the wash solution refreshed three times.

Stability Tests. Stability studies were performed in quartz cuvettes with a $1 \mathrm{~mL}$ suspension. Absorbance was recorded by UV-Vis spectroscopy over a period of $48 \mathrm{~h}$. Nitric acid (0.1 vol.\%), and fresh Aqua Regia (0.1 and 10 vol.\%), were tested for both gold and silver nanoparticles on the original aqueous suspensions, and on the single and clustered encapsulated nanoparticles suspensions. Additionally, $\mathrm{KCN}(0.2 \mathrm{M})$ was also tested for gold, and $\mathrm{H}_{2} \mathrm{O}_{2}(0.1$ vol.\%) was tested for silver. 
Cell viability studies. The nanoparticle samples were centrifuged (1000 rpm (1:60 clusters), 1500 (1:30), 2000rpm (1:20), 2500rpm (1:10), and 3000rpm (1:2.5), for 20min, 3 times) and resuspended in water to remove large aggregates, empty polymer micelles and other impurities. Cells (HeLa, A549 or human dermal fibroblast (HDF)) were grown in DMEM media supplemented with $10 \%$ FBS and $1 \%$ PS. Cells were plated at either $1 \times 10^{4}$ cells/well (HeLa and A549) or $5 \times 10^{3}$ cells/well (HDF) in 96-well plates and allowed to adhere overnight. The following day cell media was replaced with $100 \mu \mathrm{L}$ of gold and silver nanoparticles diluted in complete DMEM media; 10-fold dilutions starting from a maximum of 300 or $30 \mu \mathrm{M} \mathrm{Au}$ or $\mathrm{Ag}$ (in cell media) were used, depending on the original nanoparticle stock concentration. The initial dilution used was never below $1 / 3$, thereby minimizing the cytotoxic effects of the solvent (water). Samples were incubated with cells for $48 \mathrm{~h}$, followed by removal of the nanoparticles and application of the MTT assay (Roche), measuring the absorbance at $550 \mathrm{~nm}$. Results are expressed as a percentage of the control cell MTT absorbance value, a measure of the metabolic activity of the cells. In the case of the highest gold nanoparticle concentration $(30 \mu \mathrm{M})$, photos of the wells were taken using a Zeiss Cell Observer microscope equipped with a $20 \times$ objective (0.8 N.A) and color camera. All settings relating to photo acquisition and post processing (exposure time, gamma settings, etc.) were identical.

Cell Preparation for TEM. The cellular uptake and the stability of the polymeric shell inside the cell were confirmed using TEM. HeLa, A549 and HDF cells were plated in 12-well plates at $2 \times 10^{5}$ (HeLa, A549) or $1 \times 10^{5}$ (HDF) cells/well. The following day media was replaced with $800 \mu \mathrm{L}$ nanoparticles diluted in cell media to a final concentration of $30 \mu \mathrm{M}$. After $48 \mathrm{~h}$ incubation, nanoparticles were removed and adhered cells washed with warm media. Cells were detached using trypsin and washed numerous times with Sorensen's buffer before being fixed in a solution of formaldehyde and glutaraldehyde. Samples were embedded in agarose, dehydrated in an ethanol series, and resin embedded. 80-100 nm slides were cut on an ultramicrotome and post stained with uranyl acetate and lead citrate. TEM images were collected with a JEOL JEM- 1400PLUS transmission electron microscope operating at $120 \mathrm{kV}$, using carbon coated 400 square mesh copper grids. 
Cell preparation for reflectance and fluorescence microscopy: HeLa cells were seeded in optical microscopy 96-well plates $\left(2 \times 10^{4}\right.$ cells/well) and allowed to adhere overnight. Cell media was replaced with $200 \mathrm{ul}$ cell media containing nanoparticles at a final concentration of $30 \mu \mathrm{M}$. After $48 \mathrm{~h}$ incubation, samples were imaged without washing in confocal reflectance mode (Zeiss 880 Confocal Scanning Microscope), employing a C-Apochromat 40x objective with $633 \mathrm{~nm}$ laser source and $18 \mathrm{~nm}$ detector window between 624 and $642 \mathrm{~nm}$. All images used the same pinhole, laser power, photo acquisition and post-processing parameters. A 3-pixel median filter was applied to the reflectance channel and images are shown in original black-white and false coloured combined with brightfield transmission images. Following reflectance image acquisition, cell media was replaced with Live/dead staining fluorophores (Abcam; Apoptosis/Necrosis detection kit) and images acquired using excitation wavelengths of $405 \mathrm{~nm}$ (live fluorophore; blue), $488 \mathrm{~nm}$ (apoptosis fluorophore, green), and $597 \mathrm{~nm}$ (necrosis fluorophore, red). Again, all images used the same pinhole, laser power, photo acquisition and post-processing parameters, including a 3-pixel median filter as post-processing.

\section{References:}

[1] S. Laing, L. E. Jamieson, K. Faulds, D. Graham, Nat. Rev. Chem. 2017, 1, 0060.

[2] K. T. Nguyen, J. U. Menon, P. V. Jadeja, P. P. Tambe, K. Vu, B. Yuan, Thernostics 2013, 3, 152.

[3] X. Huang, I. H. El-Sayed, M. A. El-Sayed, Methods Mol. Biol. 2010, 624, 343.

[4] L. Scarabelli, Pure Appl. Chem. 2018, 90, 1393.

[5] J. A. Webb, R. Bardhan, Nanoscale 2014, 6, 2502.

[6] D. J. de Aberasturi, A. B. Serrano-Montes, L. M. Liz-Marzán, Adv. Opt. Mater. 2015, 3, 602.

[7] M. Salim, H. Minamikawa, A. Sugimura, R. Hashim, Med Chem Commun 2014, 5, 1602.

[8] M.-F. Tsai, S.-H. G. Chang, F.-Y. Cheng, V. Shanmugam, Y.-S. Cheng, C.-H. Su, C.-S. Yeh, ACS Nano 2013, 7, 5330.

[9] A. Taglietti, Y. A. Diaz Fernandez, E. Amato, L. Cucca, G. Dacarro, P. Grisoli, V. Necchi, P. Pallavicini, L. Pasotti, M. Patrini, Langmuir 2012, 28, 8140.

[10] P. Pallavicini, A. Dona, A. Taglietti, P. Minzioni, M. Patrini, G. Dacarro, G. Chirico, L. Sironi, N. Bloise, L. Visai, Chem. Commun. 2014, 50, 1969.

[11] S. S. Kelkar, T. M. Reineke, Bioconjug. Chem. 2011, 22, 1879.

[12] J. Xie, S. Lee, X. Chen, Adv. Drug Deliv. Rev. 2010, 62, 1064.

[13] A. McLintock, C. A. Cunha-Matos, M. Zagnoni, O. R. Millington, A. W. Wark, ACS Nano 2014, 8, 8600.

[14] H. Im, H. Shao, R. Weissleder, C. M. Castro, H. Lee, Exp. Rev. Mol. Diagn. 2015, 15, 725.

[15] P. Yang, J. Zheng, Y. Xu, Q. Zhang, L. Jiang, Adv. Mater. 2016, 28, 10508.

[16] S. Lal, N. K. Grady, J. Kundu, C. S. Levin, J. B. Lassiter, N. J. Halas, Chem. Soc. Rev. 2008, $37,898$.

[17] M. Moskovits, Rev. Mod. Phys. 1985, 57, 783.

[18] J. Wessel, J. Opt. Soc. Am. B 1985, 2, 1538. 
[19] A. Topete, M. Alatorre-Meda, P. Iglesias, E. M. Villar-Alvarez, S. Barbosa, J. A. Costoya, P. Taboada, V. Mosquera, ACS Nano 2014, 8, 2725.

[20] P.-J. Chen, Y.-D. Kang, C.-H. Lin, S.-Y. Chen, C.-H. Hsieh, Y.-Y. Chen, C.-W. Chiang, W. Lee, C.-Y. Hsu, L.-D. Liao, et al., Adv. Mater. 2015, 27, 6488.

[21] O. S. Kolovskaya, T. N. Zamay, I. V. Belyanina, E. Karlova, I. Garanzha, A. S. Aleksandrovsky, A. Kirichenko, A. V. Dubynina, A. E. Sokolov, G. S. Zamay, et al., Mol. Ther. - Nucleic Acids 2017, 9, 12.

[22] A. M. Alkilany, C. J. Murphy, J. Nanoparticle Res. 2010, 12, 2313.

[23] N. Khlebtsov, L. Dykman, Chem. Soc. Rev. 2011, 40, 1647.

[24] E. S. Melby, C. Allen, I. U. Foreman-Ortiz, E. R. Caudill, T. R. Kuech, A. M. Vartanian, X. Zhang, C. J. Murphy, R. Hernandez, J. A. Pedersen, Langmuir 2018, 34, 10793.

[25] L. L. Olenick, J. M. Troiano, A. Vartanian, E. S. Melby, A. C. Mensch, L. Zhang, J. Hong, O. Mesele, T. Qiu, J. Bozich, et al., Chem 2018, 4, 2709.

[26] K. Park, G. Tuttle, F. Sinche, S. L. Harper, Arch. Pharm. Res. 2013, 36, 125.

[27] A. Ivask, A. ElBadawy, C. Kaweeteerawat, D. Boren, H. Fischer, Z. Ji, C. H. Chang, R. Liu, T. Tolaymat, D. Telesca, et al., ACS Nano 2013, 8, 374.

[28] L. Wang, T. Zhang, P. Li, W. Huang, J. Tang, P. Wang, J. Liu, Q. Yuan, R. Bai, B. Li, et al., ACS Nano 2015, 9, 6532.

[29] B. B. Manshian, C. Pfeiffer, B. Pelaz, T. Heimerl, M. Gallego, M. Möller, P. Del Pino, U. Himmelreich, W. J. Parak, S. J. Soenen, ACS Nano 2015, 9, 10431.

[30] E. Caballero-Díaz, C. Pfeiffer, L. Kastl, P. Rivera-Gil, B. Simonet, M. Valcárcel, J. Jiménez-Lamana, F. Laborda, W. J. Parak, Part. Part. Syst. Charact. 2013, 30, 1079.

[31] R. A. Trbojevich, A. M. Torres, in Metal Nanoparticles in Pharma (Eds: M. Rai, R. Shegokar), Springer International, Germany 2017, Ch. 20.

[32] T. K. Sau, A. Biswas, P. Ray, in Metal Nanoparticles: Synthesis and Applications in Pharmaceutical Sciences (Eds: S. Thota, D. C. Crans), Wiley 2018, Ch. 6.

[33] P. Del Pino, B. Pelaz, Q. Zhang, P. Maffre, G. U. Nienhaus, W. J. Parak, Mater. Horiz. 2014, 1, 301.

[34] N. Oh, J.-H. Park, Int. J. Nanomedicine 2014, 9, 51.

[35] L. Dykman, N. Khlebtsov, Chem. Soc. Rev. 2012, 41, 2256.

[36] P. Rivera-Gil, D. Jimenez De Aberasturi, V. Wulf, B. Pelaz, P. Del Pino, Y. Zhao, J. M. De La Fuente, I. Ruiz De Larramendi, T. Rojo, X.-J. Liang, et al., Acc. Chem. Res. 2012, 46, 743.

[37] S. K. Nune, P. Gunda, P. K. Thallapally, Y.-Y. Lin, M. L. Forrest, C. J. Berkland, Exp. Opin. Drug Deliv. 2009, 6, 1175.

[38] R. Jin, Angew. Chem. Int. Ed. 2008, 47, 6750.

[39] X. Qian, X.-H. Peng, D. O. Ansari, Q. Yin-Goen, G. Z. Chen, D. M. Shin, L. Yang, A. N. Young, M. D. Wang, S. Nie, Nat. Biotechnol. 2007, 26, 83.

[40] T. Pellegrino, L. Manna, S. Kudera, T. Liedl, D. Koktysh, A. L. Rogach, S. Keller, J. Rädler, G. Natile, W. J. Parak, Nano Lett. 2004, 4, 703.

[41] C.-A. J. Lin, R. A. Sperling, J. K. Li, T.-Y. Yang, P.-Y. Li, M. Zanella, W. H. Chang, W. J. Parak, Small 2008, 4, 334.

[42] F. Zhang, E. Lees, F. Amin, P. RiveraGil, F. Yang, P. Mulvaney, W. J. Parak, Small 2011, 7, 3113.

[43] R. Asapu, N. Claes, S. Bals, S. Denys, C. Detavernier, S. Lenaerts, S. W. Verbruggen, Appl. Catal. B Environ. 2017, 200, 31.

[44] A. Sánchez-Iglesias, M. Grzelczak, T. Altantzis, B. Goris, J. Perez-Juste, S. Bals, G. Van Tendeloo, S. H. Donaldson Jr, B. F. Chmelka, J. N. Israelachvili, et al., ACS Nano 2012, 6, 11059.

[45] Y. Chen, D. Yang, Y. J. Yoon, X. Pang, Z. Wang, J. Jung, Y. He, Y. W. Harn, M. He, S. Zhang, et al., J. Am. Chem. Soc. 2017, 139, 12956.

[46] X. Li, J. locozzia, Y. Chen, S. Zhao, X. Cui, W. Wang, H. Yu, S. Lin, Z. Lin, Angew. Chem. Int. Ed. 2018, $57,2046$. 
[47] M. N. Sanz-Ortiz, K. Sentosun, S. Bals, L. M. Liz-Marzán, ACS Nano 2015, 9, 10489.

[48] J. E. Galván-Moya, T. Altantzis, K. Nelissen, F. M. Peeters, M. Grzelczak, L. M. Liz-Marzán, S. Bals, G. Van Tendeloo, ACS Nano 2014, 8, 3869.

[49] C. Hanske, M. N. Sanz-Ortiz, L. M. Liz-Marzán, Adv. Mater. 2018, 30, 1707003.

[50] D. Paramelle, D. Nieves, B. Brun, R. S. Kraut, D. G. Fernig, Adv. Healthc. Mater. 2015, 4, 911.

[51] B. Du, X. Gu, X. Han, G. Ding, Y. Wang, D. Li, E. Wang, J. Wang, ChemMedChem 2017, 12, 1768.

[52] E. Pöselt, C. Schmidtke, S. Fischer, K. Peldschus, J. Salamon, H. Kloust, H. Tran, A. Pietsch, M. Heine, G. Adam, et al., ACS Nano 2012, 6, 3346.

[53] H. Kloust, C. Schmidtke, J.-P. Merkl, A. Feld, T. Schotten, U. E. A. Fittschen, M. Gehring, J. Ostermann, E. Pöselt, H. Weller, J. Phys. Chem. C 2013, 117, 23244.

[54] H. Kloust, C. Schmidtke, A. Feld, T. Schotten, R. Eggers, U. E. A. Fittschen, F. Schulz, E. Pöselt, J. Ostermann, N. G. Bastús, et al., Langmuir 2013, 29, 4915.

[55] I. Mekis, D. V. Talapin, A. Kornowski, M. Haase, H. Weller, J. Phys. Chem. B 2003, 107, 7454.

[56] M. Rafipoor, C. Schmidtke, C. Wolter, C. Strelow, H. Weller, H. Lange, Langmuir 2015, 31, 9441.

[57] J. Ostermann, J.-P. Merkl, S. Flessau, C. Wolter, A. Kornowksi, C. Schmidtke, A. Pietsch, H. Kloust, A. Feld, H. Weller, ACS Nano 2013, 7, 9156.

[58] M. Henriksen-Lacey, S. Carregal-Romero, L. M. Liz-Marzán, Bioconjug. Chem. 2017, $28,212$.

[59] M. Mahmoudi, J. Meng, X. Xue, X. J. Liang, M. Rahman, C. Pfeiffer, R. Hartmann, P. R. Gil, B. Pelaz, W. J. Parak, et al., Biotechnol. Adv. 2014, 32, 679.

[60] T.-G. Iversen, T. Skotland, K. Sandvig, Nano Today 2011, 6, 176.

[61] C. Schmidtke, H. Kloust, N. G. Bastús, J.-P. Merkl, H. Tran, S. Flessau, A. Feld, T. Schotten, H. Weller, Nanoscale 2013, 5, 11783.

[62] N. G. Bastús, J. Comenge, V. Puntes, Langmuir 2011, 27, 11098.

[63] N. G. Bastús, F. Merkoçi, J. Piella, V. Puntes, Chem. Mater. 2014, 26, 2836.

[64] A. B. Serrano-Montes, D. J. de Aberasturi, J. Langer, J. J. Giner-Casares, L. Scarabelli, A. Herrero, L. M. Liz-Marzán, Langmuir 2015, 31, 9205.

[65] M. G. Soliman, B. Pelaz, W. J. Parak, P. del Pino, Chem. Mater. 2015, 27, 990.

[66] H. Hinterwirth, S. Kappel, T. Waitz, T. Prohaska, W. Lindner, M. Lämmerhofer, ACS Nano 2013, 7, 1129.

[67] D. N. Benoit, H. Zhu, M. H. Lilierose, R. A. Verm, N. Ali, A. N. Morrison, J. D. Fortner, C. Avendano, V. L. Colvin, Anal. Chem. 2012, 84, 9238.

[68] J. F. Hicks, D. T. Miles, R. W. Murray, J. Am. Chem. Soc. 2002, 124, 13322.

[69] C. Schmidtke, R. Eggers, R. Zierold, A. Feld, H. Kloust, C. Wolter, J. Ostermann, J.-P. Merkl, T. Schotten, K. Nielsch, et al., Langmuir 2014, 30, 11190.

[70] C.-W. Wang, A. Oskooei, D. Sinton, M. G. Moffitt, Langmuir 2010, 26, 716.

[71] S. Bals, B. Goris, L. M. Liz-Marzán, G. Van Tendeloo, Angew. Chem. Int. Ed. 2014, 53, 10600.

[72] L. Fabris, ChemNanoMat 2016, 2, 249.

[73] D. Steinigeweg, M. Schütz, M. Salehi, S. Schlücker, Small 2011, 7, 2406.

[74] D. Paramelle, A. Sadovoy, S. Gorelik, P. Free, J. Hobley, D. G. Fernig, Analyst 2014, 139, 4855.

[75] M. Fisichella, H. Dabboue, S. Bhattacharyya, M.-L. Saboungi, J.-P. Salvetat, T. Hevor, M. Guerin, Toxicol. In Vitro 2009, 23, 697.

[76] A. A. Stepanenko, V. V. Dmitrenko, Gene 2015, 574, 193.

[77] X. Ma, R. Hartmann, D. Jimenez de Aberasturi, F. Yang, S. J. H. Soenen, B. B. Manshian, J. Franz, D. Valdeperez, B. Pelaz, N. Feliu, et al., ACS Nano 2017, 11, 7807.

[78] M. Akter, M. T. Sikder, M. M. Rahman, A. K. M. A. Ullah, K. F. B. Hossain, S. Banik, T. Hosokawa, T. Saito, M. Kurasaki, J. Adv. Res. 2018, 9, 1.

[79] D. Wang, M. Hermes, R. Kotni, Y. Wu, N. Tasios, Y. Liu, B. de Nijs, E. B. van der Wee, C. B. Murray, M. Dijkstra, et al., Nat. Commun. 2018, 9, 2228. 
[80] L. Scarabelli, A. Sánchez-Iglesias, J. Pérez-Juste, L. M. Liz-Marzán, J. Phys. Chem. Lett. 2015, 6, 4270.

[81] B. Mir-Simon, J. Morla-Folch, P. Gisbert-Quilis, N. Pazos-Perez, H. Xie, N. G. Bastús, V. Puntes, R. A. Alvarez-Puebla, L. Guerrini, J. Opt. 2015, 17, 114012.

[82] R. Thiermann, W. Mueller, A. Montesinos-Castellanos, D. Metzke, P. Löb, V. Hessel, M. Maskos, Polymer 2012, 53, 2205. 